\title{
INVENTÁRIO E QUANTIFICAÇÃO DE GEOSSÍTIOS DA BACIA DE RESENDE - ESTADO DO RIO DE JANEIRO
}

\author{
Rafael Altoe Albani ${ }^{1}$, Wellington Francisco Sá dos Santos ${ }^{1}$, Ismar de Souza Carvalho ${ }^{1}$ \\ 'Universidade Federal do Rio de Janeiro, Centro de Ciências Matemáticas e da Natureza, Instituto de Geociências, Departamento de Geologia. Av. \\ Athos da Silveira Ramos, 274. Bloco F. 21941-916, Cidade Universitária, Ilha do Fundão, Rio de Janeiro, RJ, Brasil. e-mails: minerva@ufrj.br; \\ wfsasantos@gmail.com; ismar@geologia.ufrj.br
}

Recebido em 5 de março de 2014; aceito em 10 de dezembro de 2014

Resumo: A bacia sedimentar de Resende (idade Eoceno-Oligoceno) possui uma área de aproximadamente $240 \mathrm{~km}^{2}$ abrangendo os municípios de Quatis, Porto Real, Resende, Itatiaia e parte de Barra Mansa. As condições de deposição na bacia ocorreram principalmente em ambientes fluviais e de leques aluviais. A região se destaca por apresentar aspectos geológicos e geomorfológicos relevantes que podem ser utilizados para atividades científicas e educacionais. Com a intenção de preservar a geodiversidade é essencial conduzir estratégias de geoconservação, no intuito de combater as ameaças ao patrimônio geológico e manter em bom estado os geossítios da região. Para alcançar este objetivo foi feito um inventário e quantificação de cinco geossítios na bacia. Os afloramentos foram registrados, fotografados, descritos e quantificados de acordo com o seu valor intrínseco, uso potencial e necessidade de proteção. Os valores mais elevados na quantificação final foram encontrados no geossítio $2(Q=30)$ e no geossítio $1(Q=28)$. Assim, ambos podem ser considerados geossítios relevantes, tornando-se necessária a aplicação de estratégias geoconservação. O estudo contou com o apoio do CNPq, CAPES e FAPERJ.

Palavras chave: Patrimônio geológico, estratégias de geoconservação, bacia sedimentar de Resende.

Abstract: INVENTORY AND ASSESSMENT OF RESENDE BASIN GEOSITES, RIO DE JANEIRO STATE. The Resende sedimentary basin (EoceneOligocene age) has an area of approximately $240 \mathrm{~km}^{2}$ covering the municipalities of Quatis, Porto Real, Resende, Itatiaia and part of Barra Mansa. The deposition conditions in the basin occurred primarily in fluvial and alluvial fans environments. The region is notable for presenting geological and geomorphological relevant aspects that can be used for scientific and educational activities. With the intention to preserve the geodiversity is essential to conduct geoconservation strategies to combat threats to the geological heritage and maintain in good condition the geosites of the region. To achieve this aim was made an inventory and quantification of the five geosites in the basin. The outcrops were registered, photographed, described and quantified according to their intrinsic value, potential use and need for protection. The highest values were found in the final quantification in geosite $2(Q=30)$ and geosite 1 ( $Q=28)$. Thus, both may be considered relevant geosites, making it necessary to implement geoconservation strategies. The study was supported by CNPq, CAPES and FAPERJ.

Keywords: Geological heritage, geoconservation strategies, Resende sedimentary basin.

\section{INTRODUÇÃO}

A bacia sedimentar de Resende possui uma área de cerca de $240 \mathrm{~km}^{2}$ abrangendo os municípios de Quatis, Porto Real, Resende, Itatiaia e parte de Barra Mansa. As condições de deposição da bacia ocorreram predominantemente em ambientes fluviais e de leques aluviais (Ramos et al., 2006). A região se destaca por apresentar pontos de interesse relevantes associados à geologia e à geomorfologia que podem ser utilizados com interesse científico e educativo.

O Rift Continental do Sudeste do Brasil (RCSB), de idade paleógena, constitui uma área alongada e deprimida com pouco mais de $900 \mathrm{~km}$ de comprimento e pode ser dividido em três segmentos. A bacia sedimentar de Resende está localizada no segmento central, assim como as bacias de São Paulo, Taubaté e Volta Redonda (Riccomini et al., 2004). A formação do RCSB está relacionada à abertura do oceano Atlântico, em que os processos de afinamento da crosta e a acumulação de sedimentos na Bacia de Santos teriam determinado, durante o final do Cretáceo e o início do Paleógeno, um acentuado desequilíbrio isostático entre as áreas continental e oceânica. Essa tectônica geradora de blocos altos e baixos formou na Bacia de Resende dois depocentros principais, um a leste da soleira de Resende que possui profundidade estimada entre 300 e $500 \mathrm{~m}$, e outro a oeste com profundidade em torno de $300 \mathrm{~m}$ (Ramos et al., 2005).

A geodiversidade pode ser ameaçada por diferentes atividades, como por exemplo, a exploração de recursos naturais, o desenvolvimento de obras e estruturas, a gestão de bacias hidrográficas, a erosão associada ao desmatamento, reflorestamento e utilização de áreas extensas para a agricultura, atividades militares, recreativas e turísticas, coleta de amostras para fins não científicos e a falta de conhecimento do público sobre sua importância. Devido a ameaças iminentes é necessário traçar estratégias de geoconservação (Gray, 2004). Brilha (2005) realça que não se pretende conservar todos os afloramentos, mas apenas aqueles que apresentam elevado valor educativo e científico. São estes que podem ser chamados de geossítios e que, no seu conjunto, constituem o patrimônio geológico.

Grande parte do estado do Rio de Janeiro é composta por rochas cristalinas, sendo as bacias sedimentares pouco expressivas nesse estado. A 
Bacia de Resende é considerada por muitos professores da Universidade Federal do Rio de Janeiro - UFRJ como uma bacia escola. Por estar localizada próximo à cidade do Rio de Janeiro com frequência ocorrem trabalhos de campo, principalmente por estudantes de Geografia e Geologia das universidades deste estado, assim como de outros. Muitos afloramentos estão vulneráveis à destruição e degradação tornando-se imprescindível a preservação dos mesmos para que futuros estudantes possam visualizar de forma didática os processos, registros e estruturas que caracterizam uma bacia sedimentar.

O objetivo deste trabalho consistiu em fazer uma caracterização do patrimônio geológico existente na bacia sedimentar de Resende a partir da realização das duas primeiras estratégias de geoconservação apontadas por Brilha (2005), o inventário e a quantificação, para identificar, selecionar, caracterizar e quantificar os geossítios existentes na Bacia de Resende. Somente após essas etapas foi possível fazer a classificação e selecionar os geossítios mais importantes e vulneráveis para serem realizadas estratégias de geoconservação visando serem utilizados para fins educativo, científico e ainda geoturístico.

\section{MATERIAIS E MÉTODOS}

O método adotado para o desenvolvimento desse trabalho calcou-se em pesquisa bibliográfica sobre a bacia sedimentar de Resende, patrimônio geológico, geodiversidade e geoconservação. Foram realizados dois trabalhos de campo, um em fevereiro e outro em junho de 2013.

No processo de inventário foi utilizado um receptor GPS modelo Garmin 72 onde as coordenadas dos geossítios foram coletadas no formato UTM e o datum de referência utilizado foi o South American Datum de 1969 - SAD69. Neste trabalho foram selecionados cinco geossítios frequentemente utilizados em trabalhos de campo de universidades e que permitem observar aspectos relacionados à evolução geológica da Bacia de Resende. Usou-se o software ArcGIS 9.3 para a elaboração de um mapa de localização dos geossítios e da área de delimitação da bacia sedimentar de Resende. Cada geossítio foi identificado com suas coordenadas UTM, área, acessibilidade, formação geológica, membro desta formação, se é ou não uma seção tipo e o registro fotográfico. Na captura das fotografias foi utilizada uma câmera Sony modelo DSC-W630 lente Carl Zeiss Vario-Tessar de 16.1 megapixels.

A etapa de quantificação se baseou no método de Brilha (2005) e analisou os critérios intrínsecos (A), o uso potencial (B) e a necessidade de proteção
(C) de cada geossítio selecionado neste estudo. A fórmula utilizada no cálculo da quantificação final (Q) foi a de preservação a nível regional ou local, sendo ela, $Q=A+B+C / 3$, na qual quanto maior o valor de $\mathrm{Q}$ maior a importância do geossítio e, consequentemente, mais urgente é a necessidade de serem aplicadas estratégias de geoconservação.

\section{ASPECTOS GEOLÓGICOS DA BACIA DE RESENDE}

O estudo de Ramos et al. (2006) propôs uma revisão estratigráfica da sucessão de depósitos aluviais paleogênicos e neogênicos da Bacia de Resende como pode ser verificado na figura 1.

\section{Carta Estratigráfica}

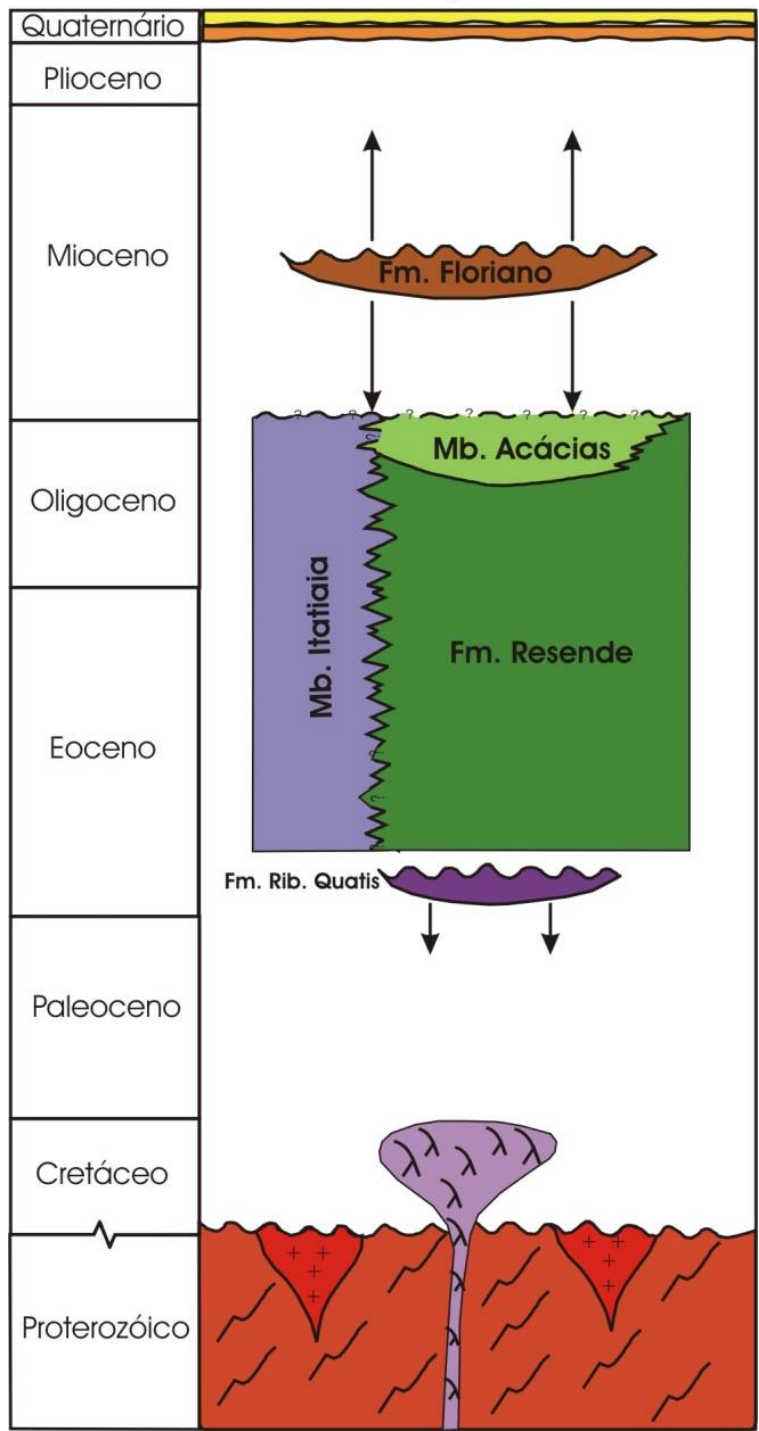

Figura 1. Carta estratigráfica da Bacia de Resende. Fonte: Ramos et al. (2006)

A Formação Ribeirão dos Quatis é a unidade cenozóica mais antiga da bacia e constitui o registro de um antigo sistema fluvial de tipo entrelaçado implantado sobre embasamento arrasado, anterior e/ou contemporâneo às primeiras manifestações da reativação do sistema de falhas ENE-WSW que gerou 
o hemigráben no início do Eoceno. A seção tipo da Formação Ribeirão dos Quatis está localizada no geossítio 1 em corte da Ferrovia do Aço.

A Formação Resende engloba a maior parte dos depósitos paleogênicos da bacia, representados especificamente por leques aluviais formados na borda norte e abundantes arenitos lamosos e lamitos arenosos derivados dos fluxos gravitacionais que penetraram na bacia através de ambas as suas bordas, bem como depósitos fluviais axiais à mesma. Constituem estes os depósitos sedimentares típicos do que é reconhecido tradicionalmente como Formação Resende. Sua seção tipo continua sendo aquela definida por Amador (1975) localizada no geossítio 2 .

Ainda de acordo com a revisão estratigráfica proposta por Ramos et al. (2006), a Formação Floriano abrange a sucessão de arenitos e pelitos interpretada como o registro de um sistema fluvial meandrante que preencheu a bacia. Foi proposta como seção tipo desta formação a sucessão de camadas lenticulares arenosas e pelíticas descrita por Carmo (1996) na estrada Agulhas Negras - Pedra Selada (RJ-161), aproximadamente a $1,5 \mathrm{~km}$ da Rodovia Presidente Dutra, mais conhecida como Via Dutra. A seção tipo originalmente definida por Amador (1975), situada na margem da Via Dutra e próxima à entrada para Floriano, como também o afloramento da Rádio Agulhas Negras encontram-se bastante degradados.

\section{RESULTADOS}

\subsection{Inventário dos geossítios}

O inventário tem como objetivo caracterizar a área de estudo e verificar se existe algo de excepcional nos geossítios. Neste trabalho foram selecionados cinco geossítios que permitem observar aspectos relacionados à geologia da bacia sedimentar de Resende e que são bastante utilizados em trabalhos de campo por professores das universidades públicas do estado do Rio de Janeiro. A delimitação da Bacia de Resende e a disposição espacial dos cinco geossítios podem ser visualizadas na figura 2 .

O afloramento que representa o geossítio 1 é caracterizado por ser a seção tipo da Formação Ribeirão dos Quatis (figuras $3 a$ e $3 b$ ) e possuir ótimas condições de observação e identificação de suas feições geológicas. Está localizado na Ferrovia do Aço na localidade de Quatis, de coordenadas UTM 23K 0580217/ 7521423. O geossítio possui uma área de $24.277 \mathrm{~m}^{2}$, podendo ser acessado pela rodovia RJ 143 por automóveis de pequeno e médio porte, adentrando a estrada paralela a linha férrea da Ferrovia do Aço. Este afloramento foi caracterizado em estudo de Albani et al. (2013), sendo composto essencialmente por sedimentos conglomeráticos.

\section{Bacia Sedimentar de Resende e localização dos geossítios}

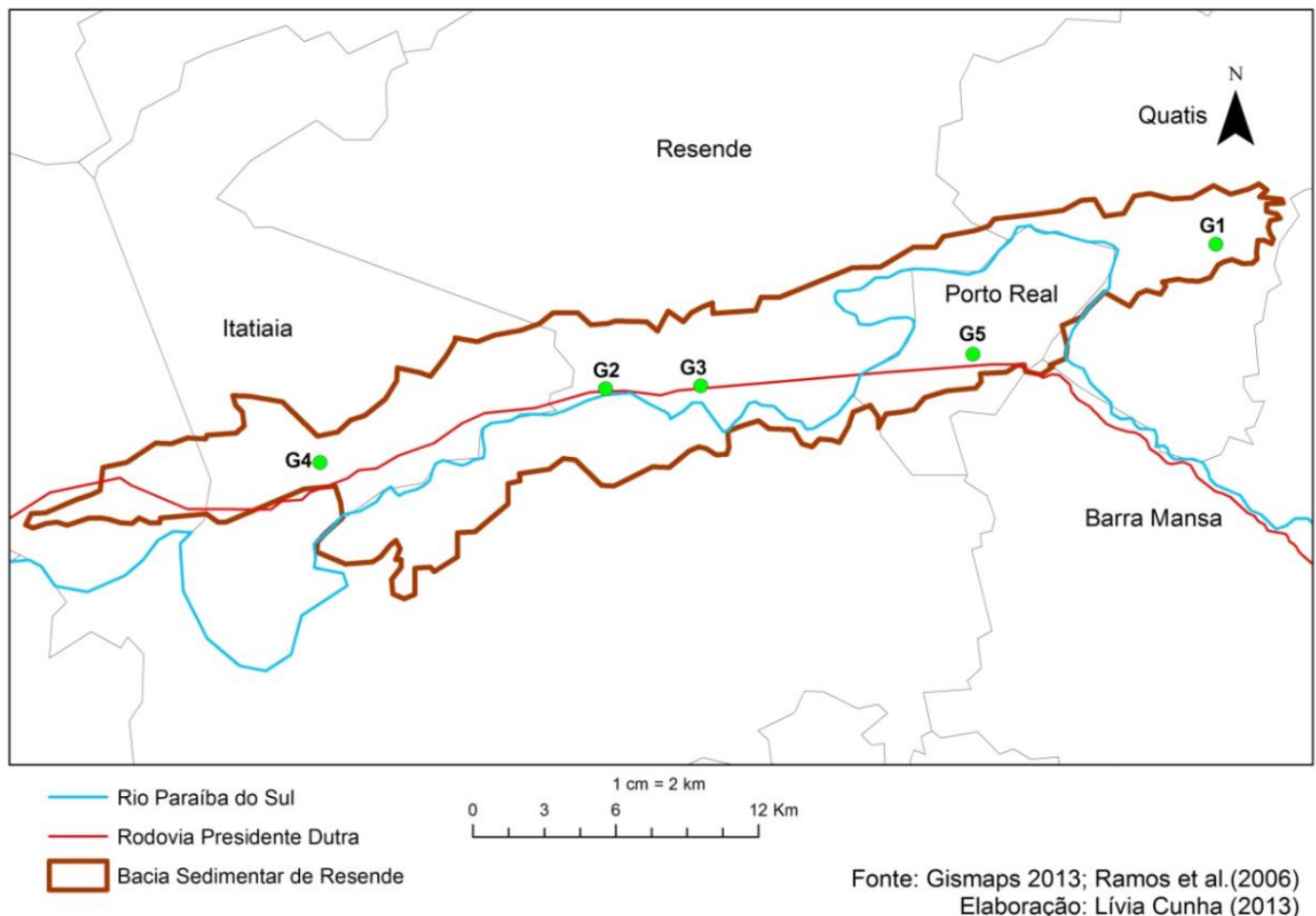

Figura 2. Delimitação da bacia sedimentar de Resende e localização dos geossítios. 
O geossítio 2 se encontra na Via Dutra, no $\mathrm{Km}$ 307,7 no sentido Rio de Janeiro - São Paulo próximo à entrada da AMAN - Academia Militar das Agulhas Negras. Afloramento que representa a seção tipo da Formação Resende (figuras $4 a$ e $4 b$ ) com boa acessibilidade, uma área de $8.273 \mathrm{~m}^{2}$ e coordenadas UTM 23K 0554783/ 7516178. Permite a visualização das sucessões fluviais com alternância de ciclos granodecrescentes e em estudos de Fernandes et al.

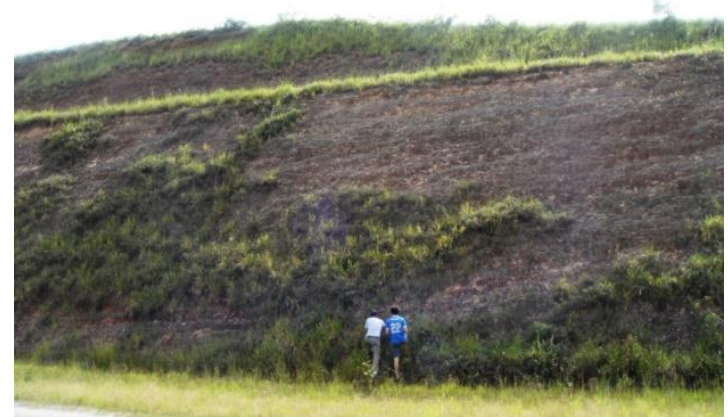

(a)
(1992) foram descritos icnofósseis do tipo skolithos.

O geossítio 3 também se encontra na Via Dutra, porém no sentido São Paulo - Rio de Janeiro, próximo ao $\mathrm{Km} 304$ e ao lado da concessionária Volkswagen. Afloramento formado por sedimentos pleistocênicos (figuras $5 a$ e $5 b$ ) com boa acessibilidade, área de $1.509 \mathrm{~m}^{2}$ e coordenadas UTM 23K 0558501/ 7516287. Possui ótima condição de visualização do antigo leito do Rio Paraíba do Sul.

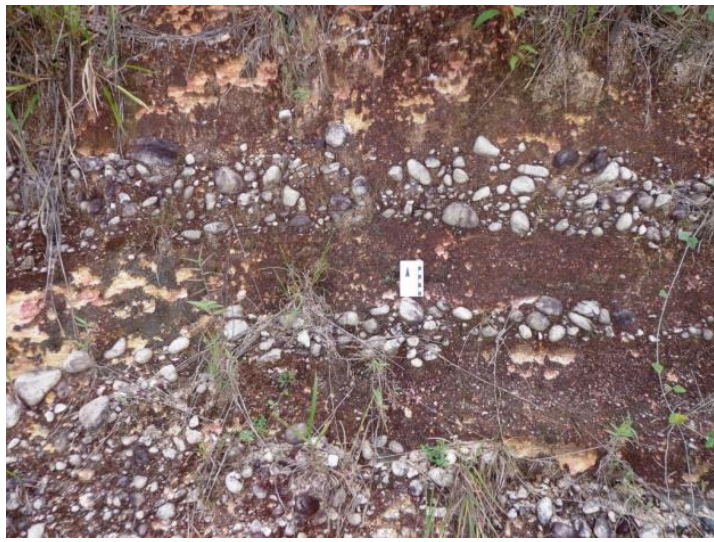

(b)

Figura 3. (a) Geossítio 1, seção tipo da Formação Ribeirão dos Quatis. (b) Camadas amalgamadas de cascalho grosso maciço depositadas por fluxos hidrodinâmicos de alta energia.

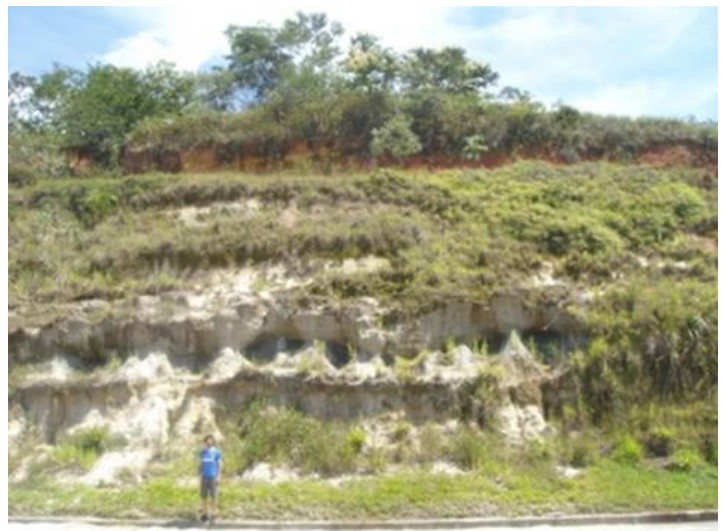

(a)

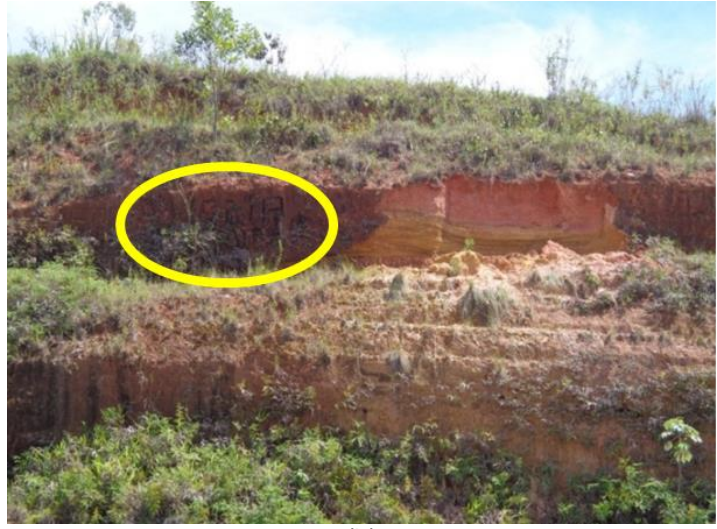

(b)

Figura 4. (a) Geossítio 2, seção tipo da Formação Resende. (b) Inscrições no afloramento representando ameaça antrópica (área destacada em amarelo).

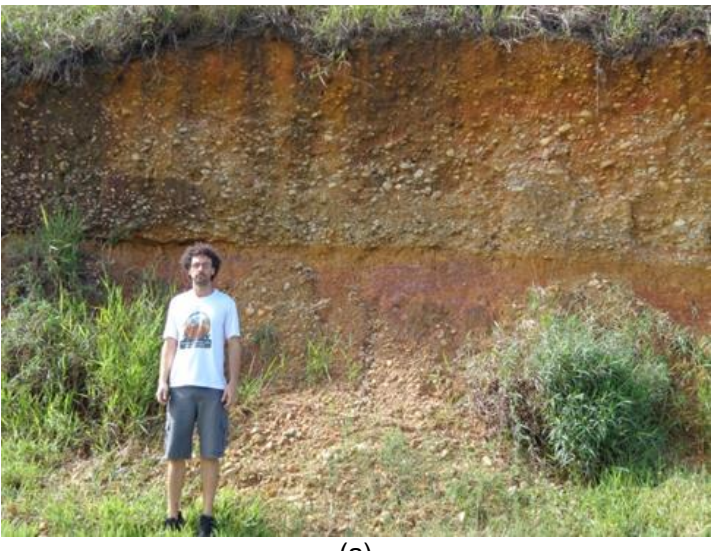

(a)

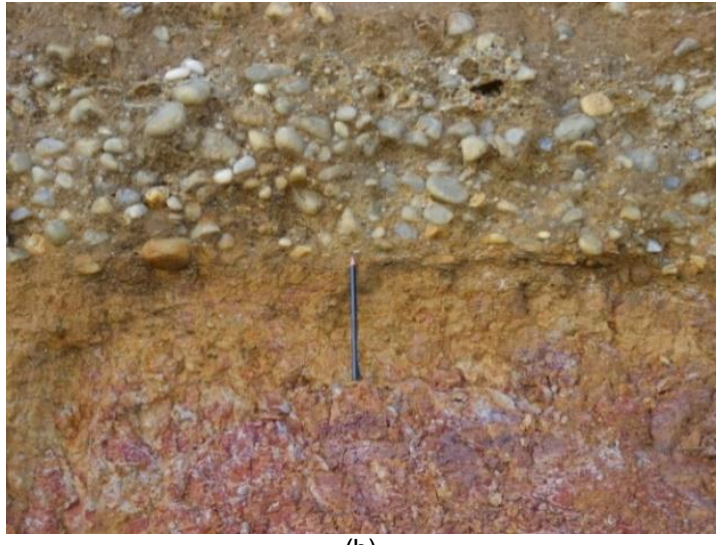

(b)

Figura 5. (a) Geossítio 3, cascalheira pleistocênica. (b) Note a discordância entre um pacote sedimentar mais conglomerático e outro mais 
O afloramento que representa o geossítio 5 (figuras 7a e 7b) fica à cerca de $300 \mathrm{~m}$ da Ponte dos Arcos, na estrada para a concessionária de carros Peugeot. Localizado nas coordenadas UTM 23K 0569052/ 7517562 possui boa acessibilidade, área de $2.467 \mathrm{~m}^{2}$ e pertence à Formação Resende, membro Acácias. Pode se observar neste geossítio dois pacotes sobrepostos, o basal de granulometria fina composto por argilito, siltito e arenito fino que indica um paleoambiente tranquilo de deposição, e o pacote superior, mais grosso, composto por arenito médio, grosso e muito grosso que indica um paleoambiente com fluxo trativo característico de ambiente fluvial de alta energia.

\subsection{Quantificação dos geossítios}

A etapa de quantificação tem por finalidade estabelecer um valor para seriar cada geossítio e, assim, definir um ranking de importância aos que devem ser conservados. Neste momento foram analisados os critérios intrínsecos $(\mathrm{A})$; sendo eles: abundância e raridade, extensão, grau de conhecimento científico, utilidade como modelo para ilustração de processos geológicos, diversidade de elementos de interesse, local tipo, associação com outros elementos de índole cultural, associação com outros elementos do meio natural e o estado de conservação; o uso potencial (B): possibilidade de realizar atividades, condições de observação, possibilidade de colheita de objetos geológicos, acessibilidade, proximidade com povoados, número de habitantes e condições socioeconômicas; e a necessidade de proteção (C): ameaças atuais ou potenciais, situação atual, interesse para a exploração mineira, valor dos terrenos (Reais $/ \mathrm{m}^{2}$ ), regime de propriedade e a fragilidade dos geossítios. Os critérios seguem o método proposto por Brilha (2005), com valores que variam de 1 a 5 . O valor determinado é adicionado à fórmula de preservação no âmbito regional / local, sendo ela $Q=A+B+C / 3$, na qual quanto maior o valor de $Q$, maior a importância do geossítio. A tabela 1 mostra os valores do somatório dos critérios de quantificação, a fórmula utilizada para a análise e a quantificação final (Q) para cada geossítio.

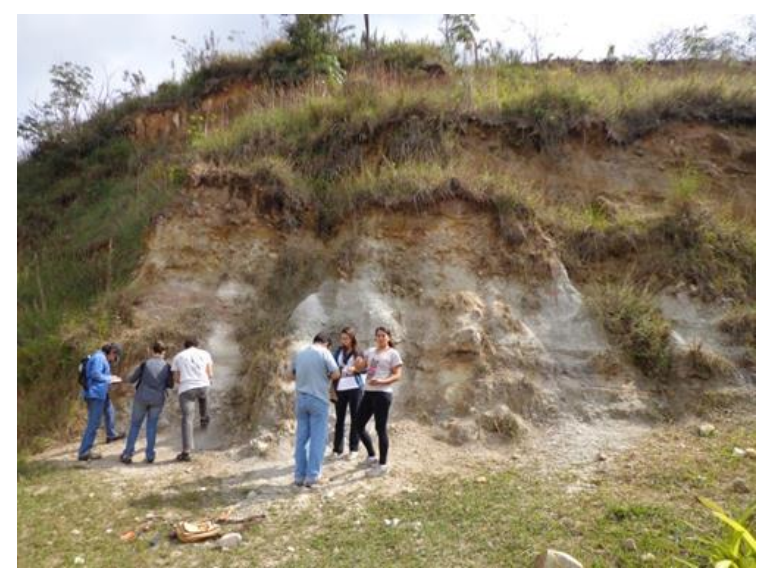

(a)

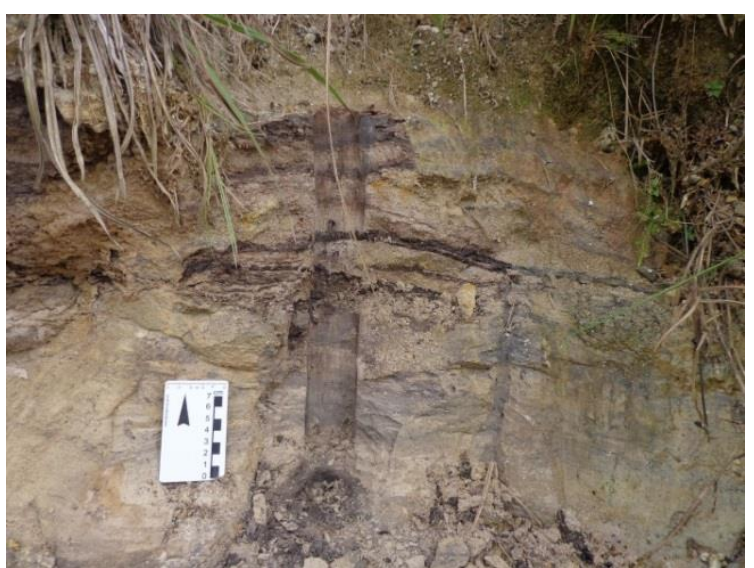

(b)

Figura 6. (a) Geossítio 4, "leque aluvial de Itatiaia". (b) Marca de testemunho retirado para análise palinológica.

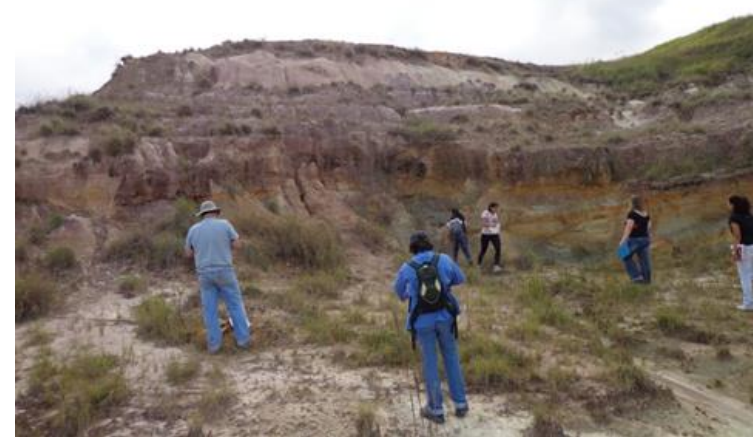

(a)

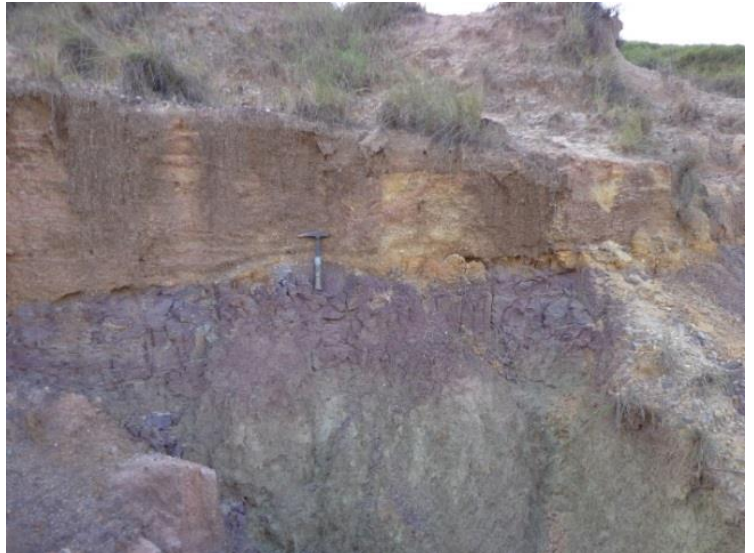

(b)

Figura 7. (a) Geossítio 5, Formação Resende, membro Acácias (b) Discordância entre o pacote basal e o superior indicando a diferença de energia dos ambientes. 
Tabela 1. Quantificação final dos geossítios.

\begin{tabular}{|c|c|c|c|c|c|}
\hline \multirow{2}{*}{ Geossítios } & \multicolumn{2}{|c|}{ Critérios da Quantificação } & A+B + C & \multirow{2}{*}{$\mathbf{Q}$} \\
\cline { 2 - 4 } & A & B & C & $\mathbf{3}$ & \\
\hline Geossítio 1 & 31 & 29 & 25 & $28,333 \ldots$ & $\mathbf{2 8}$ \\
\hline Geossítio 2 & 31 & 34 & 25 & 30 & $\mathbf{3 0}$ \\
\hline Geossítio 3 & 25 & 34 & 23 & $27,333 \ldots$ & $\mathbf{2 7}$ \\
\hline Geossítio 4 & 28 & 33 & 19 & $26,666 \ldots$ & $\mathbf{2 6}$ \\
\hline Geossítio 5 & 27 & 32 & 21 & $26,666 \ldots$ & $\mathbf{2 6}$ \\
\hline
\end{tabular}

\section{Conclusões}

A bacia sedimentar de Resende apresenta diversos geossítios que podem ser utilizados com finalidade pedagógica e científica, e que representam visualmente processos geológicos que ocorreram no passado e deixaram impressões e evidências até hoje em suas rochas. Este trabalho se propôs a realizar as duas primeiras estratégias de geoconservação, inventário e quantificação, em cinco geossítios selecionados.

A quantificação final teve maior valor no geossítio $2(Q=30)$ e no geossítio $1(Q=28)$. São classificados como local tipo e, por apresentarem os maiores valores, ambos podem ser considerados geossítios relevantes e, por conseguinte, mais urgente é a necessidade de serem aplicadas estratégias de geoconservação nestes afloramentos. Isso não significa que os outros geossítios não sejam importantes, mas é apenas uma questão de prioridade para a preservação de testemunhos geológicos únicos que se encontram ameaçados de destruição. Os geossítios localizados no entorno da Rodovia Presidente Dutra (geossítios 2, 3, 4 e 5) podem ser considerados vulneráveis por conta da erosão que ocorre naturalmente nos afloramentos e devido às ameaças antrópicas, como execução de obras e pela falta de conhecimento da importância do patrimônio geológico, evidente na figura $4 \mathrm{~b}$.

A Bacia de Resende é muito utilizada em trabalhos de campo principalmente por estudantes de universidades públicas do estado do Rio de Janeiro sendo considerada, por muitos professores, como uma bacia escola. Desta forma, é fundamental que os geossítios sejam preservados para que futuros estudantes e interessados no assunto possam visualizar de forma didática os processos, registros e estruturas que caracterizam uma bacia sedimentar. Este trabalho concluiu as duas primeiras estratégias da geoconservação, o inventário e a quantificação, com o propósito de identificar, selecionar, caracterizar e quantificar cinco geossítios existentes na bacia em estudo. Com isso foi possível fazer a classificação e selecionar os geossítios mais importantes e vulneráveis para serem realizadas estratégias de geoconservação.

\section{Referências bibliográficas}

Albani R.A., Santos W.F.S., Carvalho I.S. 2013. Características do Patrimônio Geológico da Bacia de Resende (Estado do Rio de Janeiro - Brasil). In: Anales del Encuentro de Geógrafos de América Latina, 14. Lima, Peru. Disponível em: http://www.egal2013.pe/wp-

content/uploads/2013/07/Tra_Rafael-Wellington-Ismar.pdf. Acessado em 30 de julho de 2013.

Amador E.S. 1975. Estratigrafia e sedimentação na Bacia de Resende - RJ. Anais da Academia Brasileira de Ciências. 47:181-223.

Brilha J.B.R. 2005. Patrimônio geológico e geoconservação: a conservação da natureza na sua vertente geológica. Palimage Editora, Braga, 190pp.

Carmo I. 1996. Análise estratigráfica de depósitos pleistocênicos no médio vale do Rio Paraíba do Sul (SP/RJ). Rio de Janeiro, Dissertação de Mestrado, Departamento de Geologia, Universidade Federal do Rio de Janeiro, 141 p.

Fernandes A.C.S., Borghi L., Carvalho I.S. 1992. Icnofósseis de Artrópodes da Formação Resende (Bacia de Resende, RJ). Anais da Academia Brasileira de Ciências. 64:269-275.

Gray M. 2004. Geodiversity: valuing and conserving abiotic nature. John Wiley \& Sons Ltd., Londres/Inglaterra, 434 pp.

Ramos R.R.C., Mello C.L., Sanson M.S.R. 2005. Bacias Sedimentares Brasileiras: Bacia de Resende. Fundação Paleontológica Phoenix. Ano 7, $n^{\circ} 76,6$ p.

Ramos R.R.C., Mello C.L., Sanson M.S.R. 2006. Revisão Estratigráfica da Bacia de Resende, Rift Continental do Sudeste do Brasil, Estado do Rio de Janeiro. São Paulo, UNESP, Geociências., 25:59-69.

Riccomini C., Sant'anna L.G., Ferrari A.L. 2004. Evolução Geológica do Rift Continental do Sudeste do Brasil. In: Mantesso-Neto V., Bartorelli A., Carneiro C.D.R., Brito-Neves B.B. (Org.). Geologia do Continente Sul-Americano: evolução da obra de Fernando Flávio Marques de Almeida. São Paulo: Beca, p.: 383-405.

Contribuição ao II Simpósio Brasileiro de Patrimônio Geológico

I Workshop Brasileiro de Patrimônio Geológico Construído 24 a 28 de setembro de 2013, Ouro Preto, MG 